\title{
Quantitation of digital clubbing by shadowgram technique
}

\author{
D. SINNIAH AND ASMA OMAR
}

Department of Paediatrics, University of Malaya, Kuala Lumpur

SUMMARY Finger clubbing was quantified from the magnified silhouette of the right index finger in controls and patients with clubbing, using a simple shadowgram technique. There was good correlation between clinical assessment and measurement of both the profile angle and the hyponychial angle. The hyponychial angle appeared to be a more accurate indicator of clubbing than the profile angle.

Finger clubbing was first recognised during the time of Hippocrates as an important sign of underlying pulmonary disease (Lancet, 1975). Since then it has been observed in many cardiac, hepatic, and intestinal disorders as well as in some other diseases, but there have been few attempts to quantitate the degree of abnormality (Regan et al., 1967; Bentley et al., 1976). Clinical assessment is subjective and can be difficult in mild cases. A technique that established the presence and extent of clubbing, particularly in confusing clinical situations, and which could be used to follow its course would be valuable.

Using digital cast technique, Regan et al. (1967) found that the best parameter of clubbing was the hyponychial angle. Bentley et al. (1976) measured the magnified silhouette of the index finger and also found the hyponychial angle a better indicator than the profile angle. We report a simple method of quantifying clubbing using a shadowgram technique.

\section{Materials and methods}

A standard overhead projector (3M Company) was used to project the magnified silhouette of the distal segment of the right index finger on to a screen. The finger was positioned and supported by an assistant and the image obtained was then outlined on paper. The profile and hyponychial angles were then constructed as shown in the Figure.

Those studied were: (a) 20 control subjects (10 boys and 10 girls) aged $1-12$ years (mean $6 \cdot 7 \pm 3 \cdot 4$ SD); (b) 19 patients with clinical clubbing (obliteration of the angle of the base of the nail and abnormal fluctuation) ( 9 boys and 10 girls) aged 2-12 years (mean $6.9 \pm 2.7 \mathrm{SD}$ ). The patients, comprised 10 with thalassaemia major, 5 with congenital cyanotic heart disease, 3 with malabsorption syndrome, and one with bronchiectasis. 16 of them had clubbing of

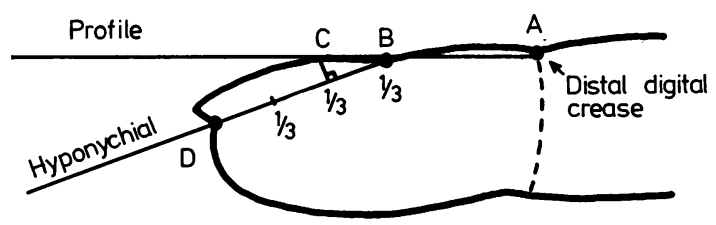

Figure Profile and hyponychial angles.

$A=$ distal digital crease. $\mathbf{B}=$ datum point (cuticle). $\mathbf{C}=$ point at which a perpendicular from one-third of the distance BD meets the nail. $\mathbf{D}=$ hyponychium (thickened stratum corneum of epidermis lying under the free edge of nail). $\mathbf{A B C}=$ profile angle. ABD $=$ hyponychial angle. (From Bentley et al., 1976).

all the fingers, while 3 had clubbing of the middle and/or ring finger but not of the index finger.

\section{Results}

The results are summarised in the Table. There were no significant differences between the sexes and mean ages of control subjects and patients $(P>0.9$; $\mathrm{P}>0 \cdot 8)$.

Profile angle. The mean profile angle of control subjects and patients was $171 \cdot 4^{\circ}\left(\mathrm{SD} \pm 5 \cdot 6^{\circ}\right.$, range $\left.154-176^{\circ}\right)$ and $182 \cdot 9^{\circ}\left(\mathrm{SD} \pm 4 \cdot 7^{\circ}\right.$, range $\left.171-189^{\circ}\right)$ respectively. There were significant differences between the mean profile angles of the two groups $(\mathrm{P}<0 \cdot 001)$.

The profile angle exceeded the normal range (171$\left.189^{\circ}\right)$ in 18 of the 19 patients and it was normal in one patient who had only slight clinical clubbing.

Hyponychial angle. The mean hyponychial angle of the right index finger of control subjects and patients

Table Profile and hyponychial angles of the right index finger of control subjects and patients with clinical clubbing

\begin{tabular}{|c|c|c|c|c|}
\hline & $\begin{array}{l}\text { Controls } \\
(n=20)\end{array}$ & $\begin{array}{l}\text { Patients } \\
(n=19)\end{array}$ & $t$ value & $\boldsymbol{P}$ \\
\hline \multicolumn{5}{|l|}{ Age (years) } \\
\hline $\begin{array}{l}\text { Mean } \\
\text { Range }\end{array}$ & $\begin{array}{l}6 \cdot 7 \pm 3 \cdot 4 \\
1-12\end{array}$ & $\begin{array}{l}6 \cdot 9 \pm 2 \cdot 7 \\
2-12\end{array}$ & 0.2 & $0.9>P>0.8$ \\
\hline Profile angle ${ }^{\circ}$ & & & & \\
\hline $\begin{array}{l}\text { Mean } \\
\text { Range }\end{array}$ & $\begin{array}{l}171 \cdot 4 \pm 5 \cdot 5 \\
154-176\end{array}$ & $\begin{array}{l}182 \cdot 9 \pm 4 \cdot 7 \\
171-189\end{array}$ & $7 \cdot 0$ & $<0.001$ \\
\hline \multicolumn{5}{|c|}{ Hyponychial angle $^{\circ}$} \\
\hline $\begin{array}{l}\text { Mean } \pm \text { SD } \\
\text { Range }\end{array}$ & $\begin{array}{l}180 \cdot 7 \pm 5 \cdot 2 \\
165-189\end{array}$ & $\begin{array}{l}194 \cdot 5 \pm 7 \cdot 5 \\
178-205\end{array}$ & $6 \cdot 7$ & $<0.001$ \\
\hline
\end{tabular}


was $180 \cdot 7^{\circ}\left(\mathrm{SD} \pm 5 \cdot 2^{\circ}\right.$, range $\left.165-189^{\circ}\right)$ and $194.5^{\circ}$ (SD $\pm 7 \cdot 5^{\circ}$, range $178-205^{\circ}$ ) respectively. There were highly significant differences between the mean hyponychial angles of the two groups $(P<0.001)$.

16 of the 19 patients had profile angles which exceeded the normal range, while 3 with clinical clubbing of the middle and/or ring finger, but not of the index finger, had normal angles. There was good correlation between the clinical diagnosis of clubbing and assessment by the shadowgram.

\section{Discussion}

Clinical assessment of finger clubbing is subjective and unreliable (Pyke, 1954; Carroll, 1972) but it is very useful as an indicator of underlying disease. The shadowgraph is a cheap and simple technique which allows serial measurements of the profile and hyponychial angles to be made speedily and without discomfort. There is excellent correlation between the clinical diagnosis of clubbing and assessment by this technique. The hyponychial angle appears to correlate more closely with the clinical diagnosis than the profile angle, as was found by Regan et al. (1967) and Bentley et al. (1976).

\section{References}

Bentley, D., Moore, A., and Shwachman, H. (1976). Finger clubbing: a quantitative survey by analysis of the shadowgraph. Lancet, 2, 164-167.

Carroll, D. G., Jr (1972). Curvature of the nails, clubbing of the fingers, and hypertrophic pulmonary osteoarthropathy. Transactions of the American Clinical and Climatological Association, 83, 198-208.

Lancet (1975). Editorial: Finger clubbing. Lancet, 1, 1285.

Pyke, D. A. (1954). Finger clubbing. Validity as a physical sign. Lancet, 2, 352-354.

Regan, G. M., Tagg, B., and Thomson, M. L. (1967). Subjective assessment and objective measurement of finger clubbing. Lancet, 1, 530-532.

Correspondence to Professor D. Sinniah.

\title{
Fatal bleeding from gastric ulceration during first day of life-possible association with social stress
}

\author{
R. J. PUGH, R. W. NEWTON, AND D. M. PIERCY \\ Departments of Paediatrics and Pathology, Hull Royal Infirmary, North Humberside
}

SUMMARY Death from haemorrhage is described in a 21-hour-old baby boy with acute gastric ulceration. Particular note is made of the very high level of psychosocial maternal stress during the last trimester of pregnancy. A causal relationship of this stress and the peptic ulceration is suggested, with gastrin as the mediator.

A 17-year-old primigravida was admitted in labour after an uncomplicated pregnancy and monitored cardio-tocographically without causing concern. The first stage of labour lasted 5 hours and the second 20 minutes, producing a healthy baby boy at term, weighing $2.73 \mathrm{~kg}$, by a spontaneous normal vaginal delivery. The Apgar score was 4 at one minute and 8 at five minutes. No special resuscitative procedures were needed, no nasogastric tube was passed, and vitamin K $1 \mathrm{mg}$ was administered intramuscularly.

The baby had normal infant care alongside its mother, taking $5 \%$ dextrose solution eagerly by bottle until, at age 20 hours, fresh blood was vomited and shown by Apt's test to be of infant origin. Clinical examination then showed a vigorous baby with no purpura, bruising, or haemangiomata. There was no family history of bleeding disorder, and no aspirin or similar drugs had been administered to the mother at the relevant time. The mother was in good health. A venous blood sample on admission at 20 hours showed the baby to have a haemoglobin of $14 \cdot 2 \mathrm{~g} / \mathrm{dl}$, a platelet count of $160 \times 10^{9} / 1(160000 /$ $\mathrm{mm}^{3}$ ), and no abnormality in the prothrombin, partial thromboplastin, or thrombin times. A similar coagulation screen of the mother's blood was also normal.

During the next half-hour further fresh blood was vomited repeatedly, resulting in a critical degree of shock with apathy and loss of awareness. A catheter introduced into the inferior vena cava via the umbilical vein recorded a low central venous pressure and $75 \mathrm{ml}$ of O-negative whole blood was transfused rapidly with only fleeting benefit. Death supervened at 21 hours, only one hour after the first haematemesis.

Necropsy showed the source of bleeding to be 3 areas of gastric ulceration: 2 on the posterior wall and one on the greater curvature (Figure). Histological examination showed that they were of the acute peptic 